\title{
Las tensiones en algunas Tradiciones de Don Ricardo Palma en la Huamanga colonial
}

Por Marcial Molina Richter 
Profesor principal de Literatura de la Universidad Nacional de San Cristóbal de Huamanga. Fundador del Círculo de Literatura Javier Heraud y del Teatro Experimental Ayacucho. 


\section{En torno a las tensiones}

En el libro Formas sociales de aprendizaje en la educación contemporánea, decíamos: "Acaso no es una verdad cuando se afirma que el mundo de hoy no es igual al mundo de ayer"... En efecto, muchas concepciones paradigmáticas, que encendieron serias polémicas y cerraron el siglo pasado para dar inicio al presente llamado: Era del conocimiento científico, han sufrido serios reveses y han resucitado y posesionado viejas concepciones remozadas, nuevas por un lado, y por otro, han dado paso a la era de las metáforas o de las denominaciones: la era del conocimiento científico, el neoliberalismo, la globalización, la dependencia planetaria, la interculturalidad, la competitividad e hipercompetitividad, por no decir imperialismo y práctica a ultranza del reino de la economía neoliberal, cuyo poder traspasa las fronteras de lo nacional y desestabiliza estados, gobiernos, instituciones y toda forma de organización social, política, económica y cultural.

No estaría exento de razón alguna quien deseara preguntar qué tiene que ver esto con el enunciado de la presente disertación. Mucho. Pues quienes dominan el universo, por la caducidad e insostenibilidad de sus expresiones en una sociedad de cambios unilaterales, al no tener el contrapeso de la balanza por la caída de los países llamados socialistas, han denominado 
a las contradicciones, con un término más digerible y menos problemático: Las tensiones.

Las tensiones o contradicciones, problemas, controversias, dificultades... pertenecen a una sinonimia, cada una con sus gradaciones correspondientes. Por tanto, han existido y existirán mientras existán el universo, la humanidad, o sea el hombre y la realidad.

La naturaleza de las tensiones pueden ser de dos clases: a antagónicas y no antagónicas. Las primeras se dan entre los grupos económico-sociales que detentan el poder económico, político, social cultural y entre aquellos desposeídos que no poseen poder alguno más que sus fuerzas de trabajo. Las segundas - no antagónicas- se dan en el seno de los desposeídos.

En la presente disertación se trata de precisar las características de las tensiones en algunas tradiciones de Don Ricardo Palma, en la Huamanga Colonial; pero previamente veamos algunas caracterizaciones del escenario de los hechos en la colonialidad.

\section{Referencias espacio-temporales}

Desde el momento que iniciamos los estudios y las referencias sobre Huamanga en las Tradiciones de don Ricardo Palma, fue una constante señalar las caracterizaciones sociales y culturales de la Huamanga Colonial. Al respecto, las podemos sintetizar en algunos hechos importantes, a saber:

2.1.- La ciudad de Huamanga corresponde a la denominación tomada desde su fundación ocurrida el 25 de abril de 1540, en el lugar que hoy ocupa, y que en ese momento era un valle abundante en vegetación, bañado por un cristalino riachuelo cuyo nombre era Pukaray. 
2.2.- En diversas fuentes históricas se habla de una primera fundación, que en efecto ocurrió un 29 de enero de 1539 con el nombre de La Villa de Joan de la Frontera en el lugar denominado por los nativos como Guamanga, cercano a la Pampa de Ayacucho.

2.3.- Al respecto, el maestro y escritor Juan Perlacios Campos escribió:

"La ciudad de Huamanga sufrió también los problemas de las guerras civiles entre los conquistadores, que luego de la "Batalla de Chupas", entre las fuerzas de Diego de Almagro "El Mozo" y "Cristóbal de Vaca de Castro", con el triunfo de este último a favor de la corona española, que le otorgó el título de La Muy Noble y Leal Ciudad de San Juan de la Victoria de Huamanga.

Luego, en la ciudad y en la región se inició un proceso de distribución de tierras, con muchas dificultades por la ambición y acaparamiento de ellas, así como el despojo de las tierras de los nativos.

Posteriormente se organizó políticamente la Región, con la creación del Corregimiento de Huamanga, siendo cabeza de región que tenía bajo su cargo los partidos o provincias de Huamanga, Huanta, Angaraes, Castrovirreyna, Huancavelica, Lucanas, Parinacochas, Vilcashuamán y Andahuaylas...".

2.4.- Una de las fuentes ineludibles la constituye “...los estudios realizados por el Dr. Lorenzo Huertas quien considera que una de las etapas más importantes de Huamanga es la de Asentamiento y Apogeo que abarca desde su fundación hasta fines del siglo XVII. En dicho documento se afirma: 
“...En consecuencia, se convirtió la ciudad en ciudad de frontera y ciudad de asentamiento. Frontera porque permitió el control militar de los continuos levantamientos de los pobladores, y de asentamiento, porque posibilitó la residencia de los dueños y administradores de las minas de Huancavelica que por el clima adverso no se prestaba para la residencia. Por otro lado, estratégicamente la ubicación de la nueva ciudad era favorable para el paso entre Lima, Cusco y La Paz. La nueva ciudad empezó a construirse según la concepción feudal española, como se puede notar en la actualidad por la disposición de las plazas, calles, templos, casonas, etc. Es la época de la repartición de tierras e indios y la consiguiente explotación mediante el sistema del latifundio y la servidumbre. La institución que más tierras poseía fue el clero, erigido como uno de poderes fuertes dentro de la colonia, con decisión política y económica..."

3. Las tensiones, su carácter y las formas cómo se resuelven en algunas Tradiciones de Don Ricardo Palma

Para el desarrollo de este acápite se han seleccionado tres tradiciones emblemáticas que, aparte de contener el referente espacial, temporal y cultural de la Huamanga Colonial, son precisamente representativas de esas tensiones y se dan entre los personajes que no tienen acceso al poder y los que detentan el poder eclesiástico y civil de esa época.

\subsection{El niño llorón}

Es una tradición clásica de Don Ricardo Palma ambientada en la Huamanga colonial de 1675. Se trata de la vida conyugal entre el zapatero remendón Perico Urbistondo -mellado en 
sesos- casado con la vivaracha Casilda. Así pues, por razones de trabajo se ausenta el primero a la ciudad de Huanta, no sin antes recomendarle el cuidado de su consorte al Niño Jesús bellamente tallado y, para consuelo del remendón, confidente de sus penurias. Al retorno de su viaje, al día siguiente, Don Perico no encontró a su consorte. Por el contrario halló la puerta cerrada. A sus llamados y a golpes de la puerta acudió doña Pulquería, una vieja cucufata y chismosa. Esta le informó en una larga perorata que apenas él había puesto los pies en camino, su consorte se había entregado a los brazos de Alberto Quiñónez, "un mozo quisquilloso, coco de mozas y quebradero de cabeza de mozas casquiluchas".

Don Perico forzó la puerta y constató que no estaba su adorada esposa; entonces se dirigió al cuarto donde estaba el Niño Dios. Al llegar, cogiendo una lezna se la clavó diciéndole:

“iAh, ingrato! ¿Así vigilas por mi honra y pagas mi cariño?”

A todo esto, la vieja que estaba fuera escuchó el llanto de un niño; ingresó a sabiendas que el matrimonio no tenía hijos y encontró a Perico desmayado con una lezna en la mano. Entonces acudieron los vecinos y socorrieron al zapatero, quien contó que después de haber herido al Niño Dios, este prorrumpió en llanto.

\subsubsection{Tensiones Antagónicas y no Antagónicas:}

Del argumento se deduce la presencia de dos tipos de contradicciones o tensiones que son antagónicas y no antagónicas.

\subsubsection{La primera corresponde a:}

- La relación entre los esposos Perico Urbistondo y Casilda, frente a Quiñones, que por deducciones pertinentes se 
infiere que son tensiones irreconciliables, por cuanto responde a un grupo social antagónico,

- La relación indirecta entre Pulqueria y Quiñones, en cambio, es de carácter antagónico porque pertenecen a diferentes grupos sociales con actividades económicas contrarias y con un carácter que media entre denuncia y desprecio al sujeto aprovechador de las mujeres.

\subsubsection{La segunda tensión se presenta en:}

- La relación entre los esposos Perico Urbistondo y su esposa Casilda, que se manifiesta a todas luces, a nivel de pueblo: dada la infidelidad de la primera, se disuelve el matrimonio. Como consecuencia de la resolución de esta tensión, Perico ingresó al convento de Ocopa, donde murió en condición de Lego; mientras, Casilda pierde a su esposo y es abandonada por el seductor para terminar de prostituta.

- La relación de los esposos Perico y Casilda con la chismosa Pulqueria (populachera, parlanchina, correveidile...) tiene un carácter no antagónico por cuanto dicho vínculo, con una situación económica disminuida, se produce entre los componentes del pueblo.

\subsection{Un obispo de Ayacucho}

Esta tradición muy representativa se remonta a los años de 1782, que corresponde al apogeo de la gran ciudad de Huamanga, cuando ya estaba en funcionamiento la Real y Pontificia Universidad de San Cristóbal de Huamanga, fundada como tal el 3 de julio de 1677. En el seno del Clero habían demasiadas intrigas, tanto fue así que el primer 
Obispo Fray Agustín de Carbajal murió envenenado en 1618. Igualmente, tuvieron la misma suerte los Obispos Zárate, La Fuente, Matienzo y otros. Es curioso cómo nuestro tradicionista nos reporta que siete obispos de Huamanga fallecieron antes de completar los dos años de residencia en la ciudad...

El héroe resulta siendo Don Francisco López Sánchez, que en el año de 1782 entró como vigésimo Obispo de la Diócesis de Huamanga. Físicamente era alto, robusto, un español raro, muy trabajador, de carácter demasiado fuerte pero oportuno, que ponía en buen camino al clero Huamanguino que tenía en ese entonces costumbres muy relajadas.

La tradición, en resumen, muestra a una autoridad eclesiástica mitad militar y mitad sacerdote. Con el primer carácter, de soldado, cuando no se avenía "a las buenas" cualquier interlocutor al frente, arremetía a sopapos y puntapiés para hacerse entender y obedecer con el más pintado de los que se ponían al frente. Es decir, el mitrado, según nuestro tradicionista, "era ligero de manos y de pocas pulgas". Pero es necesario recalcar que el clero en esa época en Huamanga "era torpe, ignorante, servil, crapuloso y desaseado, porque muchos sacerdotes más parecían cocineros que ministros de Dios por la vestimenta", situación contrariada con las cualidades del Obispo López Sánchez, porque su usía era “... moral instruido, generoso, caritativo y muy amigo de chistes y agudezas".

Descrito someramente el ambiente de la Huamanga Colonial de ese entonces y de la presencia inequívoca del venerable carácter del Obispo López Sánchez, en relación a su entorno en el cumplimiento de su misión sagrada, encontramos las siguientes tensiones: 
3.2.1. Tensiones antagónicas y no antagónicas:

Primera Tensión:

En 1783, el Obispo en mención había ordenado reparar el salón Episcopal. Pero como el albañil lo había hecho con ropas propias de trabajo y cubierto el rostro con un pañuelo, a modo de paliacate, él se encontraba así trabajando. En ese momento fue sorprendido por un monigote que buscaba a la autoridad máxima del clero huamanguino. Al verlo, y tomándolo por albañil, le preguntó por el Obispo. De hecho se molestó Don Francisco, y bajándose del andamio, "se encaró al petulante", diciéndole "Bellaco, ¿no tengo cara de Obispo?". A lo cual el monigote se deshizo en excusas. Pero el prelado le reiteró: "Estoy en mi casa y hago lo que me da la gana". Una vez enterado de la causa de la visita del aspirante a vestir órdenes, fue citado para otro día. Llegada la fecha del examen sinodal, el Prelado le preguntó: “¿Qué hace Dios en los cielos?”, a lo cual respondió sin ninguna turbación el examinando: "Ilustrísimo señor, hará lo que le dé su real gana que para eso está en su casa”.

Ante semejante y cautivante respuesta, lejos de enojarse el Obispo López hizo del "agudo cleriguillo uno de sus familiares favoritos".

De lo descrito se deduce que se trata de una tensión no antagónica y su carácter pertenece al seno del grupo social conservador, pues el monaguillo al asumir un nuevo rol dentro de una organización eclesiástica de carácter conservador, asume las responsabilidades y funciones propias de esa organización social, más aún cuando no existe incompatibilidad de pensamientos. 
Segunda Tensión:

Durante el ejercicio del Obispado, a cargo del prelado López Sánchez, la Diócesis de Huamanga, vivía tiempos difíciles: por un lado había abundantes clérigos y por otro escasos los pagadores de misas. La pobreza afectaba grandemente al clero de conformidad con lo descrito por nuestro gran tradicionista.

Un día llegaron noticias, ante el Obispo Francisco López, de que un clérigo, al no encontrar sufragantes para las misas, se había dedicado al oficio de oficial de sastre, para mantenerse y sostener a su anciana madre enferma. No faltaron las envidias de los otros frailes y llegaron los chismes a los oídos de Monseñor López, quien ordenó inmediatamente que lo trajeran ante él.

Cuando estuvo el curita frente al prelado, este le dio un puñetazo a la vez que le decía:

“-iPara qué te ordenaste, si tenías tanta inclinación a la aguja y al dedal?".

Frente a tal situación el sacerdote, repuesto de la bofetada, con serenidad y firmeza encaró a la autoridad eclesiástica diciéndole que si había tomado esa decisión no fue una traición a sus santos quehaceres, aun menos para buscar y alimentar vicios, sino más bien para dar pan a su anciana madre -que además se encontraba enferma- luego que en su juventud había trabajado tanto para que él se ordene de sacerdote. Además -le siguió diciendo- Qué podría hacer si escaseaban las misas y por tanto no iba a dejar morir a mi madre.

Ante tan sincero y real alegato, se le salieron las lágrimas al Señor Obispo y en un instante de inspiración abrazó al 
curita, a la vez que le decía que le absolvía de cualquier calumnia y, por el contrario, le aseguró que al día siguiente le entregaría el título de Cura Interino de Acobamba, el más rentable curato de la comarca.

Tensiones Antagónicas y no Antagónicas:

En este nuevo episodio, que indudablemente es muy emotivo, la tensión se establece entre el Señor Obispo, máxima autoridad del clero de Huamanga de ese entonces, con un curita de barrio con escasos recursos económicos. En consecuencia, se establece una tensión no antagónica en el seno de una misma institución: la Iglesia Católica.

Las partes en aparente contienda, no obstante pertenecer a una misma institución conservadora, con un gran poder representativo por una lado y marginado por el otro, de todos modos controversiales por los roles que cumplen, tienen una carácter no antagónico, por lo que la solución indudablemente tiene esa misma naturaleza. Esta situación pone en evidencia que las tensiones, al interior de los grupos de poder, por más discrepancias que existan, se resuelven de modo no antagónico, con lo cual se mantiene el estatus de poder por una parte $y$, por otra, de sujeción.

Finalmente el maestro de nuestras Tradiciones Peruanas, en la misma tradición aludida, nos muestra una tensión mayor:

\section{Tercera Tensión:}

Esta dificultad constituye una expresión muy espectacular respecto a la conducta de algunos sacerdotes, entonces entregados a las pasiones mundanas reñidas con la 
formación de los curas, pero que en una realidad como la de Huamanga Colonial sucedió $-y$ tal vez pudo suceder después- puesto que la fama de los huamanguinos, en todos los tiempos, traspasan las fronteras del país por ser músicos, bohemios, guitarristas, charangueros, zapateadores, peleadores, robacorazones, en fin, de otras cosas más.

En la época a la que nos remontamos, un día, el Sr. Obispo Francisco López paseaba en coche con su familia por las calles de Huamanga. Ya próximo al Convento de Santa Teresa, ordenó se detuviera el coche en la puerta de una tienducha, por cuanto se escuchaban los bullicios propios de una chichería. No era para menos: aproximadamente seis muchachas cholonas, con faldas levantadas formaban una ronda cogidas de las manos. Seis voces aguardientosas cantaban canciones obscenas acompañadas de un charango y una guitarra. Al centro del ruedo, con la sotana "hecha un asco", se encontraba un clérigo conocido como "Yaya Pipingo" que en castellano quiere decir "Padre Pipingo", quien botella en mano se despabilaba con canciones obscenas a los oídos del Santo Obispo. Al ver esta escena, el Obispo Francisco López, ordenó a su pertiguero que lo encerrara en el calabozo al clérigo inmundo.

Para nuestro propósito aquí se establece nuevamente una tensión no contradictoria en el seno de una misma institución conservadora, pero con asomo de convertirse en una tensión antagónica.

\section{Tensión Cuarta:}

Como se habrá advertido, esta cuarta tensión expresa las contradicciones al interior de la Iglesia Católica y, 
más aún, entre sus ministros. En efecto, el Sr. Obispo es el representante del poder eclesiástico y, por entonces, irrefutable poder por sobre los demás poderes políticos, económicos, sociales y culturales.

La dificultad configurada en un espacio y una época determinados por las situaciones dadas deviene en una tensión antagónica; por tanto, la solución responde a ese nivel puesto que al interior subyacen intereses de mayor trascendencia cuya solución conduciría a la desaparición de una de las partes.

La situación descrita hasta este instante, tal cual se observan al interior de la institución eclesiástica que representa a un poder del Estado, un poder absoluto en la Huamanga Colonial, conduce, de conformidad con los hechos narrados, a una agudización y a una conversión, en una situación insostenible que concluye con la eliminación violenta de una de las partes en contienda.

Hemos de reiterar con las propias palabras de don Ricardo Palma, que la "...corrupción del clero, en la época del Señor López Sánchez, era espantosa." No obstante, su empresa moralizadora, con empeño y crudeza, era superior a sus fuerzas humanas, por lo mal terminaría de manera misteriosa y escandalosa.

La tenacidad moralizadora con que enfrentó a la corrupción, el Obispo López Sánchez y a los que le precedieron, fueron estériles porque el mal tenía hondas raíces, ya que iban surgiendo algunos grupos de poder político y económico que signarían el advenimiento de la debilitación del poder eclesiástico y el anuncio de un posible activamiento burocrático con nuevos actores en el escenario económico y político. 
Entre los sacerdotes a quienes el Señor Obispo había suspendido por sus conductas inadecuadas, reñidas con la moral, estaba el curita apodado "Humán Coles", que significa -Cabeza de Col- quien pertenecía a una de las familias antiguas y ricas de la ciudad. Aunque ignorantón, engreído de su abolengo y fortuna, era el autor de pasquines y caricaturas contra el Obispo Francisco López.

Una mañana nuestro Obispo moralizador se enteró de otra de las hazañas del curita "Humán Coles", quien en un estado de beodez había dibujado un mapa en el rostro de una mozuela.

Muy exaltado se paseaba el Obispo cuando de pronto se presentó el insolente cura en completa borrachera. Y cuando empezaba a subir las gradas, Monseñor López Sánchez, indignado, le aplicó un soberano puntapié en el pecho que lo hizo descender a trancos. Pero este, cogido de la balaustrada, muy insolente gritó:

- "Auila llaipas patalla mantacca" (Miren iqué gracia! Hasta mi abuela puede pegarme desde arriba pues estoy abajo). Felizmente no hubo más incidentes por cuanto los familiares intervinieron y lo llevaron al calabozo. Al final, premonitoriamente, el Prelado sentenció:

- "Está bien. No saldrá del encierro hasta que se enmiende o yo sucumba”

El conflicto descrito al interior de uno de los poderes más notorios de un Estado -La Iglesia Católica-, como en el caso de Huamanga de ese entonces, por haber llegado a su clímax, tenía indudablemente que concluir con la desaparición de una de las partes en conflicto por haber devenido en una tensión o contradicción antagónica. 
Monseñor continuó con sus tareas moralizadoras cuyo corolario fue la infatigable Reforma del Clero en Huamanga, con visitas al interior.

Un día apareció sentado en su sillón, con una carta en la mano: iEstaba muerto!

Se cree que le dieron un veneno muy poderoso. La opinión pública de Huamanga de ese entonces señalaba con el dedo acusador al curita "Human-Coles"

Terminada la tensión antagónica por la desaparición de una de las partes, se resolvió el problema de modo violento. La situación, prevista por cuanto había llegado a su máxima expresión contradictoria, exigía la desaparición de una de las partes en conflicto.

\section{Bibliografía}

DELGADO, Washington, Historia de la Literatura Republicana. Ediciones Rikchay Perú. 2da edición Lima, 1984.

INSTITUTO RICARDO PALMA, Aula Palma III 2002-2003.

MOROTE BEST, Efraín: Huamanga una larga historia. CONUP Lima, 1974.

MOLINA RICHER, Marcial, La Fiesta de la Lira, Temas de Literatura. Editorial San Marcos, 2012.

PALMA, Ricardo: Tradiciones completas. Edit. Aguilar. Madrid, 1957.

SANTILLANA CANTELlA, Tomás: Ayacucho en las Tradiciones Peruanas de Ricardo Palma. 
PERLACIOS CAMPOS, Moisés, Personalidades de Huamanga. NOVA SAV G.R.A.F.

SOTO, Clodoaldo, Literatura Ayacuchana de los últimos cincuenta años. Trabajo de investigación. Ayacucho, 1982. 